\title{
FutureJournal
}

\section{Modelagem Estatística para Suportar as Decisões sobre Eficácia de Mídia: Estudo de Caso em uma Empresa de Telecomunicações}

\section{Julia Pinheiro Rizzi}

MBA em Gestão Empresarial pela Fundação Instituto de Adminsitração, FIA, Brasil.

juliaprizzi@gmail.com

\author{
Ailton Conde Jussani \\ Professor de Pós-graduação Lato Sensu da Fundação Instituto de \\ Administração, FIA, Brasil. \\ ailtoncj@uol.com.br
}

\section{RESUMO}

O investimento em publicidade no Brasil cresceu 55\% entre 2010 e 2014, fortemente puxado pelos meios de comunicação de massa, que seguem uma tendência de queda de audiência sem que haja uma redução correspondente no seu custo. Esse comportamento explica-se em grande medida pelo modelo híbrido de remuneração de agências de comunicação no país: parte feita pelo anunciante e outra pelos grandes veículos, em especial os de televisão. Adicionalmente, as métricas tradicionais utilizadas para definição do plano de mídia levam em consideração variáveis como cobertura e frequência, que privilegiam veículos de massa e não levam em consideração o resultado de venda gerado, fator determinante para as empresas. Tomando-se como base um estudo de caso em uma empresa de banda larga residencial em São Paulo e Rio de Janeiro, neste trabalho objetiva-se contribuir para o processo de decisão de compra de mídia, identificando os meios e os formatos de mídia mais eficazes nos canais de venda receptivos. No estudo, apresenta-se uma modelagem estatística que destaca o resultado incremental de cada meio e seu respectivo custo, demonstrando aqueles que trazem maior retorno de venda ao negócio. Os resultados apontam que os meios e formatos que mais receberam aporte de investimento não tiveram melhor desempenho, enquanto outros com investimento menos representativo demonstraram potencial para alavancar o resultado da empresa, ao apresentar melhor custo-benefício. Conclui-se, portanto, que há alternativas mais eficazes para a empresa estudada, por meio de ajuste no mix de mídia. 


\section{FutureJournal}

PALAVRAS-ChaVe: Modelagem estatística. Mix de mídia. Eficácia de mídia. Tomada de decisão.

\section{Statistical Modeling to Support Decisions on Media Efficacy: a Case Study in a Telecommunication Company}

\section{ABSTRACT}

Investment in advertising in Brazil grew 55\% in the last five years, strongly pulled by the mass media, which have been presenting a downward in trend audience without a corresponding reduction in cost. This behavior is explained largely by the hybrid payment model of communication agencies in the country: part of the payment is made by the advertiser and the other part by large vehicles, especially television. Additionally, the traditional metrics used to define the media plan take into account variables such as reach and frequency, which favor mass media vehicles and ignore the result of sales, a determining factor for companies. Based on a case study in a residential broadband company in São Paulo and Rio de Janeiro, this study aims to contribute to the media buying decision process, identifying the most effective medium and format of advertising in sales receptive channels. The study uses statistical models to highlight the incremental result of each medium and its cost, highlighting those that bring higher return on sales to the business. The results show that the media and formats that received the greatest investment did not present better performance, while others with a less representative investment demonstrated potential to leverage the company's results, presenting better cost-effectiveness. It follows, therefore, that there are more effective alternatives of advertising investment for the company by adjusting the media mix.

KEY-WORDS: Statistical modeling. Media mix. Media efficacy. Decision making. 


\section{INTRODUÇÃO}

A promoção (ou comunicação) é um dos quatro pilares do composto de marketing, juntamente com preço, praça e produto (McCarthy, 1996). Uma das principais ferramentas de comunicação é a propaganda, que cumpre seu papel de informar, influenciar consumidores potenciais, gerar lembrança da marca, agregar valor à marca e ao produto e ainda auxiliar os demais esforços da empresa, dentre eles alavancar as vendas (Crescitelli \& Shimp, 2012).

Segundo o Ibope (2015), o mercado de telecomunicações é o sétimo que mais investe em propaganda no Brasil, com as principais empresas do setor figurando no topo da lista nacional, conforme demonstrado na Tabela 1, a seguir. O elevado volume de investimento dessas empresas em propaganda torna inevitável o questionamento quanto ao efetivo resultado gerado pelo esforço de comunicação.

Tabela 1: Ranking de anunciantes do Brasil em 2013

\begin{tabular}{c|c|c}
\hline $\begin{array}{c}\text { POSIÇÃO NO } \\
\text { RANKING 2013 }\end{array}$ & ANUNCIANTES & R\$ (000) \\
\hline 9 & Telefônica (marca Vivo) & 1.172 .919 \\
\hline 13 & Sky Brasil & 1.057 .046 \\
\hline 23 & Oi & 763.820 \\
\hline 24 & Tim Brasil & 754.786 \\
\hline 28 & Claro & 657.052 \\
\hline 30 & Net Comunicação & 584.352 \\
\hline
\end{tabular}

Fonte: Ibope (2015)

A mensagem de propaganda e a mídia que a transmite são indissolúveis. A mensagem é eficaz apenas quando colocada na mídia e nos veículos que melhor alcançam o público-alvo a um custo justificável. Podemse distinguir duas formas gerais de mensurar o resultado de determinada campanha: por meio de pesquisas de eficácia de mídia e de pesquisas de eficácia de mensagem (Crescitelli \& Shimp, 2012). Para esta última, são aplicadas pesquisas qualitativas e/ou quantitativas que mensuram se determinada campanha foi agradável, foi relevante, passou a mensagem 
principal, gerou lembrança, gerou interesse pelo produto, gerou associação à marca, etc.

Mesmo assumindo que haja uma forte interdependência entre mensagem e mídia para o sucesso de uma campanha, este trabalho se debruçará especificamente sobre o tema de eficácia de mídia.

\subsection{SITUAÇÃO-PROBLEMA}

O investimento em propaganda no setor de telecomunicações cresce a cada ano no Brasil e, no segmento específico de banda larga residencial, o comportamento se repete. Acompanhando esse cenário de investimento crescente, observa-se no mercado de publicidade queda na audiência dos principais meios de massa, em especial TV e jornal, e crescimento acelerado no meio internet e demais mídias emergentes. A estratégia de investimento em cada meio de comunicação e seu custo, entretanto, não acompanharam na mesma medida essa mudança no mercado (Court, Gordon \& Perrey, 2005).

As métricas tradicionais utilizadas para definição do plano de mídia, aplicadas pelas agências de comunicação, são crescentemente questionadas pelos seus anunciantes, que respondem com desconfiança às recomendações de investimento que permanecem privilegiando mídias de massa em detrimento de novas mídias. Essa desconfiança é agravada pelo modelo híbrido de remuneração das agências de publicidade, que têm nas mídias de massa uma fonte relevante de receitas. Soma-se a isso o fato de que as métricas utilizadas não levam em consideração o resultado de venda gerado, fator determinante para as empresas (Court et al., 2005).

A definição do mix de comunicação de uma campanha publicitária, antes considerado um processo seguro, tem se tornado arriscado, pois envolve um grande número de variáveis. Esse novo entendimento abre caminhos para a construção de um modelo que utilize uma métrica que combine mídias tradicionais e emergentes, aumente a eficiência na compra e maximize o resultado de venda. 


\subsection{OBJETIVOS}

À luz de técnicas de estatística, neste trabalho objetiva-se identificar os meios e os formatos de mídia mais eficazes nos canais de venda receptivos em uma empresa de telecomunicações do setor de internet fixa residencial nas cidades de São Paulo e Rio de Janeiro.

Para isso, dois objetivos específicos devem ser atingidos:

1. medir o efeito do esforço de comunicação sobre os contatos realizados nos canais de venda receptivos, determinando a participação de cada meio de comunicação no resultado observado;

2. determinar o investimento de cada meio de comunicação necessário para gerar um contato nos canais de venda receptivos.

\subsection{CONTRIBUIÇÕES}

Ao profissional de comunicação, o estudo fornecerá ferramenta que auxiliará a tomada de decisão de investimento em comunicação, uma das linhas de orçamento mais representativas das grandes empresas, focando o esforço financeiro em meios que maximizem o resultado nos canais de venda.

Este material contribuirá também para a academia. Durante a fase de levantamento de referência bibliográfica, nenhum material científico nacional foi encontrado em relação à eficácia de mídia, sob a ótica dos diferentes efeitos da comunicação nos canais de vendas. Estudos norte-americanos trazem contribuições interessantes para o tema, porém com modelos matemáticos complexos para aplicação em empresas, demandando uso de ferramentas específicas e especialistas em estatística.

\section{FUNDAMENTAÇÃO TEÓRICA}

\subsection{EVOLUÇÃO DO MERCADO PUBLICITÁRIO NO BRASIL}

O mercado de mídia no Brasil cresce a cada ano. Anunciantes investem numa quantidade crescente de mídias, procurando garantir o 
contato entre sua mensagem e seus consumidores, o que eleva consideravelmente o custo de uma campanha (Briggs, Krishnan \& Borin, 2005). Segundo dados coletados no Ibope Monitor (2015), representados no Gráfico 1, o investimento de mídia no mercado brasileiro cresceu 55\% entre 2010 e 2014. Nesse mesmo período, o mercado de telecomunicações cresceu ainda mais: $79 \%$.

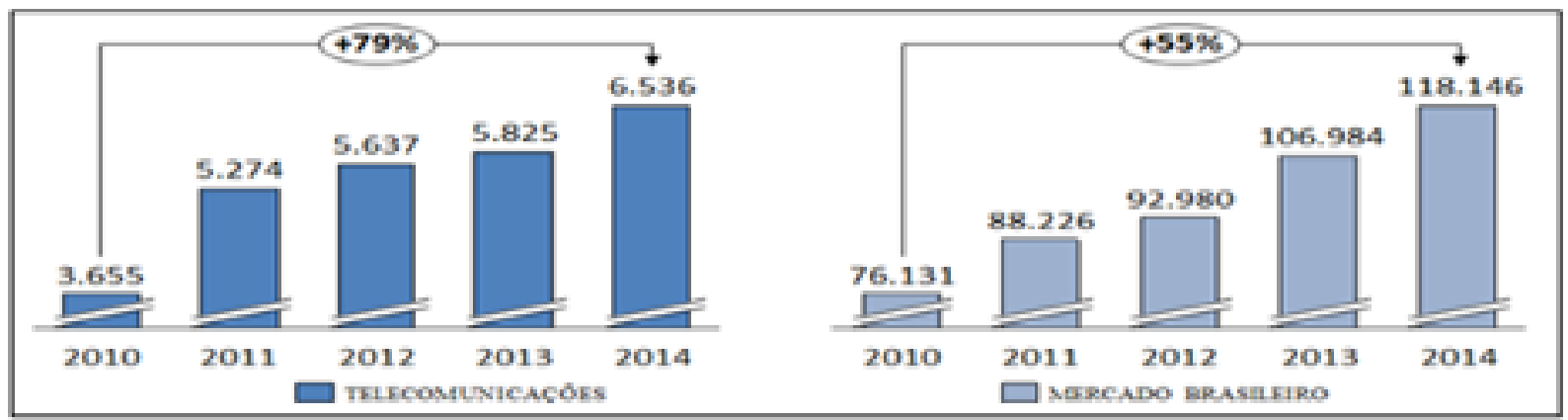

\section{Gráfico 1: Evolução de investimento em mídia no Brasil (em R\$ milhão)}

Fonte: Ibope Monitor (2015)

Ainda com base nas informações do Ibope Monitor (2015), o mercado de banda larga residencial, no segmento de telecomunicações, também acompanha esse movimento de crescimento, conforme representado no Gráfico 2. Observa-se nos últimos cinco anos crescimento de $100 \%$ de investimento nesse mercado, $14 \%$ na cidade de São Paulo e $73 \%$ na cidade do Rio de Janeiro. Juntas, essas duas praças representam $41 \%$ do total de investimento de banda larga residencial no Brasil.

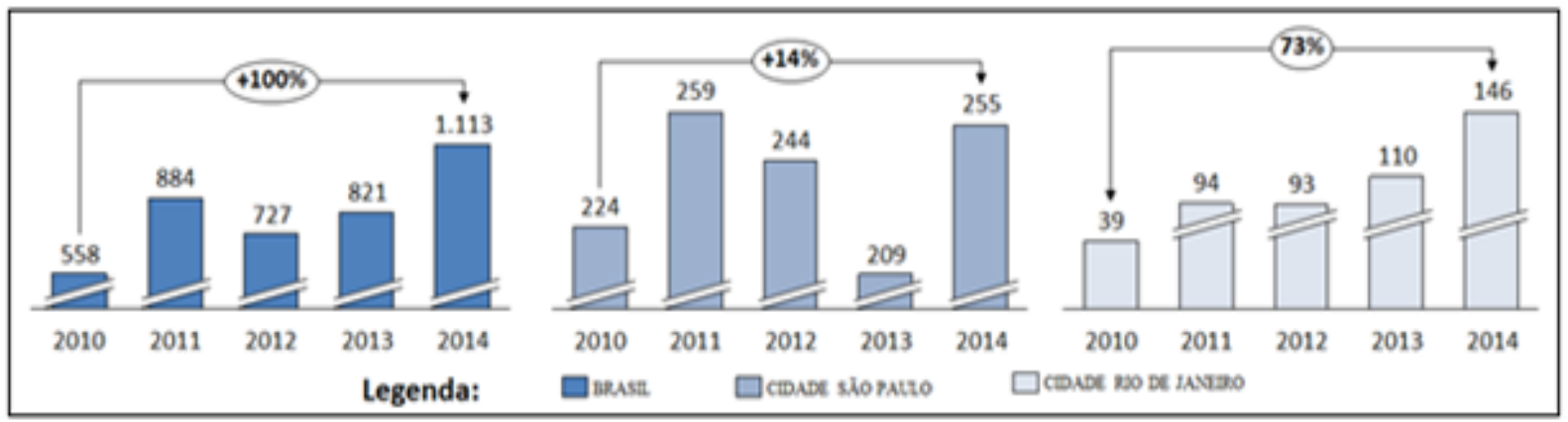

Gráfico 2: Investimento de banda larga residencial (em R\$ milhão)

Fonte: Ibope Monitor (2015) 
Ao observar-se o mix de meios, torna-se evidente que o crescimento no volume investido tem relação direta com o aumento de investimento no meio TV, que continua sendo a mídia de massa mais utilizada pelos anunciantes. Conforme demonstrado no Gráfico 3, em 2014, ela foi responsável por $60 \%$ do total da verba investida em mídia em todos os setores e 68\% no setor de telecomunicações (Ibope Monitor, 2015). Apesar dos crescentes investimentos publicitários, a TV aberta também enfrenta desafios: a audiência média das principais emissoras está em queda e a tendência é que a queda continua nos anos subsequentes (Ibope Monitor, 2015).

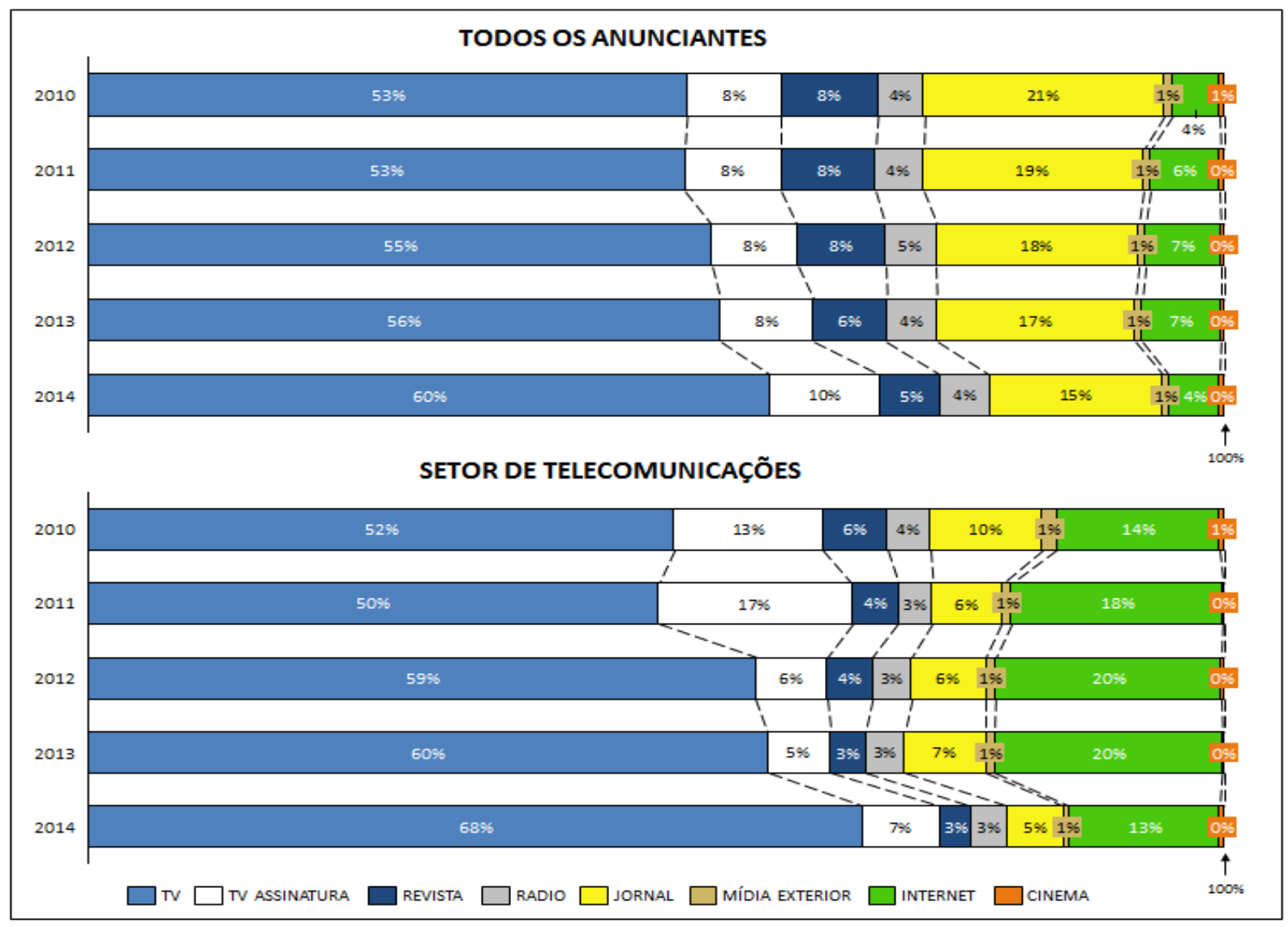

\section{Gráfico 3: Mix de Mídia Brasil}

Fonte: Ibope Monitor (2015)

Levantamento no mercado norte-americano realizado por Steinberg (2009) indica ainda que o ambiente de negócios das mídias vem atravessando grandes mudanças. Além da queda de audiência, outras formas de consumo de vídeo ganharam espaço. Em 2009, o video on demand alcançou $42 \%$ das 
famílias norte-americanas. No mesmo ano, mais de um quarto dos lares norte-americanos já contava com gravadores digitais de vídeo, e o consumo de vídeos nas redes sociais registrou aumento anual de 98\%. Para o autor, há uma mudança não só na forma de distribuição de conteúdo, mas também na forma de rentabilizar esse conteúdo, com mais players disputando a verba publicitária que antes ia somente para as redes de TV.

Em paralelo, as novas mídias digitais experimentaram uma expansão acentuada no mercado brasileiro. Entre 2010 e 2013, enquanto o investimento publicitário em internet cresceu 139\%, o mercado total de mídia cresceu 41\% (Ibope Monitor, 2015). Blogs, sites de internet, redes sociais, celulares e consoles de videogame, chamados de novas mídias ou mídias emergentes (Dimmick, Kline \& Stafford, 2004; Coulter \& Sarkis, 2005), transformam consumidores passivos de informação e entretenimento em programadores de TV, DJs, produtores e distribuidores de conteúdo. $\mathrm{O}$ consumidor conquistou o direito de definir a própria grade de programação, regulando sua exposição à publicidade enquanto consome seu conteúdo predileto (Anderson, 2008). Em suma, a audiência de um anúncio traduz cada vez menos a atenção que o consumidor dedicou àquele anúncio (Donaton, 2004). De forma consonante, Court et al. (2005) argumentam que essa escassez compromete a eficiência das mídias e das estratégias de marketing dos anunciantes.

Por tudo que foi visto, ficam evidentes as dificuldades que os anunciantes brasileiros enfrentam atualmente para comunicar-se com seus clientes. Assim, devem repensar suas estratégias para integrar da melhor forma possível mídias tradicionais e emergentes, buscando aumentar a rentabilidade e a eficiência de suas campanhas (Briggs et al., 2005).

\subsection{PROCESSO DE DEFINIÇÃO DO MIX DE MÍDIA}

A definição do mix de mídia depende fundamentalmente da escolha e do uso adequado de métricas. Com as métricas, os anunciantes avaliam o desempenho de cada mídia de suas campanhas, direcionando seu investimento àquelas mais rentáveis (Shen, 2002). Segundo Crescitelli e 
Shimp (2012), a forma de utilização de mídias de massa tradicionais é pautada em seis métricas:

1. alcance (ou cobertura) - percentual do público-alvo impactado pela campanha num período predeterminado, geralmente um mês;

2. frequência - quantidade de vezes, em média, que os membros de um público-alvo são expostos à mensagem do anunciante em um espaço de quatro semanas;

3. peso - determinação do volume de propaganda necessário para obterse um alcance predeterminado para a campanha. No meio TV, por exemplo, são amplamente utilizados o Gross Rating Point (GRP) e o Target Rating Point (TRP), como referências;

4. continuidade - determinação do cronograma de mídia, definindo pela continuidade da comunicação, atuação em ondas (oscilação de intensidade ao longo do tempo) ou determinação de flights (blocos de campanha bem definidos, com períodos sem veiculação), modelo mais adotado por anunciantes em função da restrição de orçamento;

5. recência - relacionado à frequência com a qual uma mesma pessoa deve ser impactada pela comunicação, defendida amplamente como pelo menos três vezes. O princípio da recência (ou modelo do espaço na prateleira) afirma que a indústria da propaganda não conseguiu provar o valor do critério do alcance eficaz 3+ (Ephron, 1995);

6. custo - alocação do orçamento de mídia nos distintos meios e veículos. Um dos indicadores mais importantes e universalmente usados é o critério custo-por-mil (CPM). Vale considerar, entretanto, que esse indicador trata da eficiência de custo, e não necessariamente de eficácia. Outra importante limitação diz respeito à falta de comparabilidade de mídia, dado que cada meio desempenha um papel diferente e, portanto, naturalmente possui CPMs distintos.

Historicamente, verifica-se dentre os anunciantes e as agências uma predileção pelo uso de métricas de audiência, estimulando naturalmente o investimento nas mídias tradicionais e influenciando diretamente o ritmo de adoção das novas mídias. Os próprios anunciantes alimentam essa relação de dependência ao traduzir muitas de suas metas de campanhas em números de audiência e concluem que a sua inaptidão em trabalhar com métricas diferentes da audiência limita a capacidade de enxergar oportunidades em 
sua periferia, embora reconheçam a necessidade de encontrar caminhos alternativos (Rodrigues, Chimenti \& Nogueira, 2012).

Segundo Rodrigues, Chimenti, Nogueira \& Vaz (2013), após realizarem entrevista com anunciantes de diversos setores econômicos do país, observou-se que o discurso dos entrevistados apontou novas métricas, como as de atenção, como uma inovação bem-vinda, tendo em vista o ambiente de negócios marcado pela necessidade crescente de monitorar a rentabilidade das mídias. No entanto, uma análise mais aprofundada das entrevistas indicou que, muitas vezes, as métricas de atenção e sua riqueza de formatos trouxeram mais desconforto do que soluções, em parte justificado pelo desconhecimento delas. Mesmo quando plenamente compreendidas, as métricas de atenção traziam consigo outro desafio: comparabilidade. Para os entrevistados, a dificuldade de comparar medidas de atenção com métricas de audiência complicava a avaliação de performance de campanhas e prejudicava a gestão de investimentos publicitários.

Conforme apontam Chimenti e Nogueira (2007), as métricas adotadas não são o único empecilho para adoção de novas mídias em campanhas publicitárias. Esse comportamento tem como agravante o modelo de negócios das agências de publicidade no país. O relacionamento das agências com os anunciantes é marcado por um cenário de desconfiança mútua e dependência. Nelas, há um conflito de interesses na determinação de seu real cliente, pois, embora sejam oficialmente os anunciantes, estas têm no bônus por volume (BV), pago pelos grandes veículos, suas maiores fontes de receita. Somada a isso, a inexistência na maior parte das empresas de uma área independente das agências para aferir e monitorar o resultado das campanhas faz com que os anunciantes se tornem dependentes das recomendações feitas pelas agências, que têm nesses fatores destacados um grande estímulo à concentração de investimentos em mídias tradicionais em detrimento das emergentes (Rodrigues et al., 2012).

Na seção a seguir, tratar-se-á especificamente sobre os diversos efeitos do composto de marketing, em especial da comunicação, sobre as vendas em uma organização, apontando caminhos e os principais desafios para viabilizar a construção de um modelo que combine mídias tradicionais e 
emergentes, aumente a eficiência na compra e maximize o resultado de venda.

\subsection{OS EFEITOS DO COMPOSTO DE MARKETING SOBRE AS VENDAS}

Tellis (2006) identifica sete importantes padrões de comportamento nos canais de venda em resposta à exposição de mídia: efeito corrente, efeito de forma, efeito competitivo, efeito residual, efeito dinâmico, efeito de conteúdo e efeito de mídia. Os quatro primeiros também reagem a outros estímulos, como mercado competitivo e variações na oferta.

1. Efeito corrente (ou atual): mede a variação das vendas no exato momento da exposição de mídia. Vale reforçar que o efeito corrente em resposta a uma variação de preço é em média 20 vezes maior que o de mídia (Sethuraman \& Tellis, 1991), sendo fundamental considerar a variável oferta no modelo.

2. Efeito residual: é observado após a exposição de mídia. Este efeito retardado das vendas pode ocorrer em função de diversos fatores, incluindo - mas não se restringindo - a demora para ação do consumidor após ser impactado, o boca a boca gerado pela campanha, etc. Nos gráficos B e C do Gráfico 4, mostram-se duas curvas distintas para representar esse efeito, que pode ter curta ou longa duração, sendo o primeiro mais comum. 


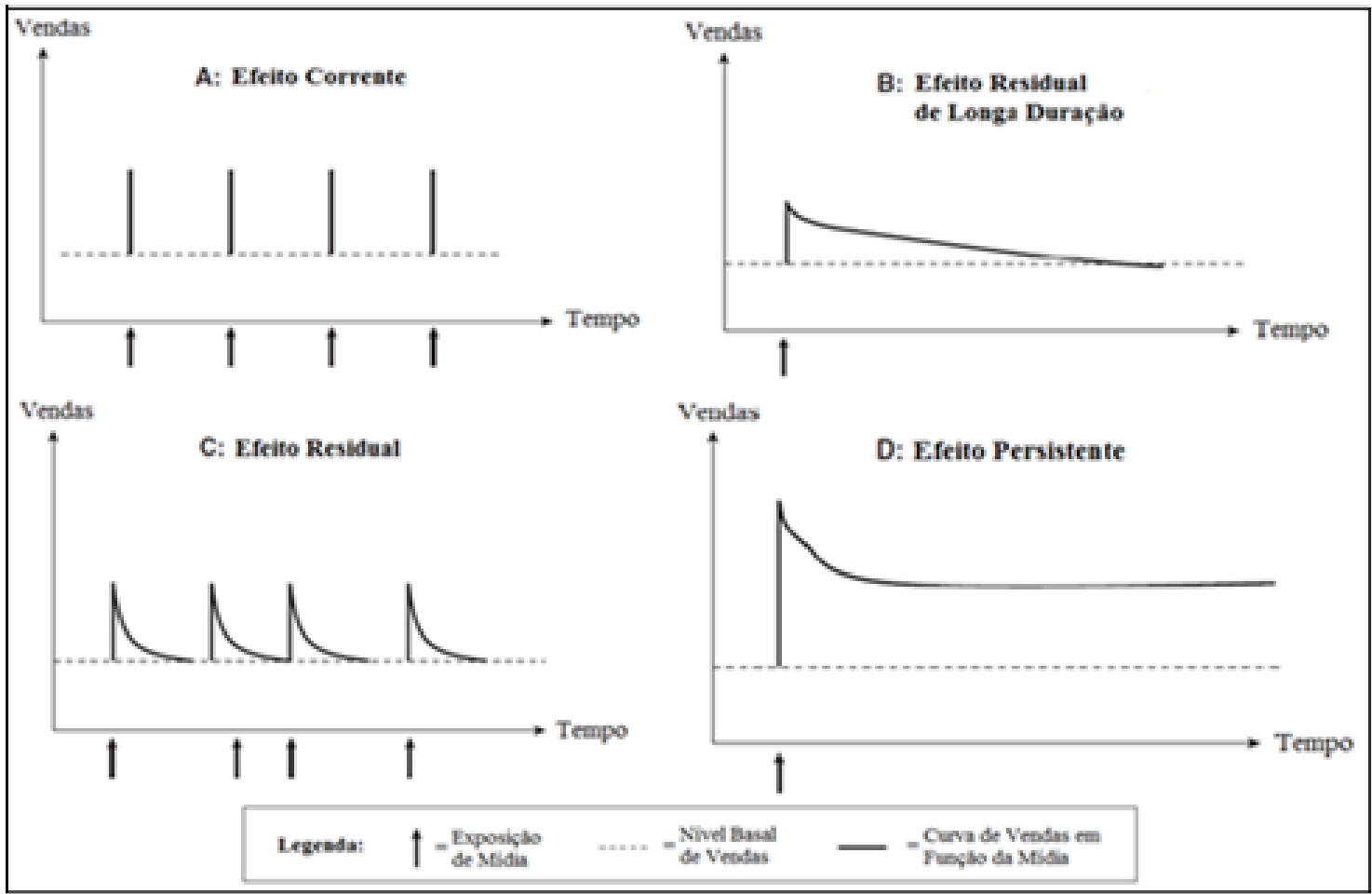

Gráfico 4: Efeito temporal da exposição de mídia

Fonte: Adaptado de Tellis (2006)

3. Efeito de forma: corresponde ao efeito da curva de vendas em resposta a um aumento na intensidade de exposição de mídia. No Gráfico 5, demonstram-se três curvas, sendo a em formato de $\mathrm{S}$ a mais aceita por Tellis em seu estudo. Essa curva pressupõe a necessidade de atingir uma intensidade mínima para que o resultado de vendas comece a fazer efeito e segue um crescimento linear até um ponto em que se observa uma saturação. A principal restrição à representação do efeito linear é que esta pressupõe que as vendas crescerão indefinidamente até o infinito conforme a intensidade de mídia cresce, o que não é plausível. 


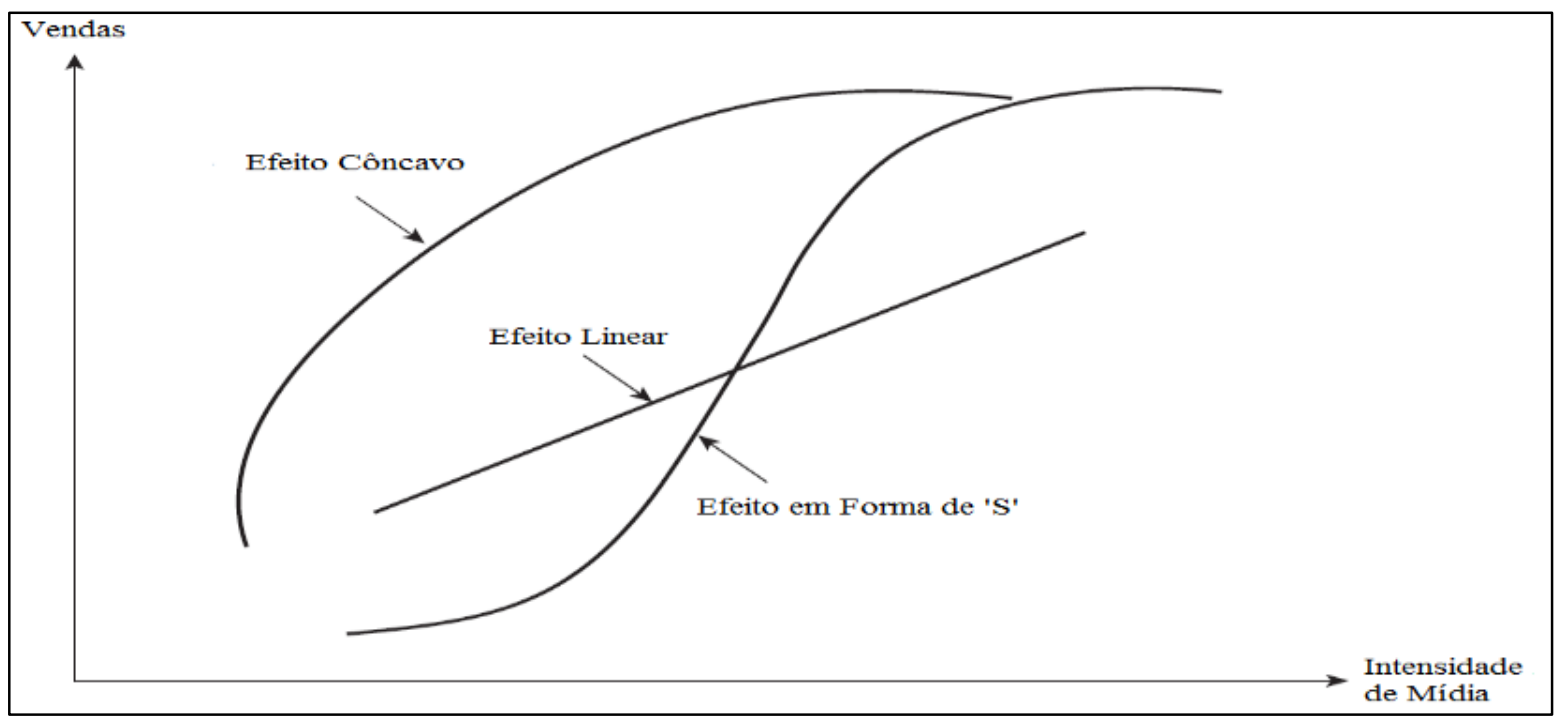

Gráfico 4: Efeitos lineares e não lineares à exposição de mídia

Fonte: Adaptado de Tellis (2006)

4. Efeito competitivo: assume que o resultado de uma ação de comunicação depende também da intensidade de comunicação do mercado como um todo, sendo aconselhável a inclusão da intensidade de mídia da concorrência na modelagem.

5. Efeito de conteúdo: é o efeito de vendas em resposta ao conteúdo de uma campanha. Campanhas diferentes estimulam de forma distinta as pessoas, podendo gerar mais ou menos vendas, conforme a clareza da informação, a criatividade, a capacidade de viralização nas redes sociais, etc. Este efeito é para Telles o mais desafiador para a modelagem, pois não se tem de forma objetiva a correlação entre mensagem e a resposta gerada.

6. Efeito de mídia: é o efeito distinto gerado pelos diferentes meios e formatos de comunicação. Por exemplo, os mesmos $\mathrm{R} \$ 1.000$ reais investidos em rádio ou em jornal geram resultados distintos. O mesmo ocorre dentro de um mesmo meio, como o de TV para formatos distintos: duas inserções avulsas de 30 segundos num intervalo comercial ou um merchandising dentro de um programa com 60 segundos de duração.

7. Efeito dinâmico: altera-se ao longo do tempo. Tem relação com a curva em $\mathbf{S}$ do efeito de forma. Nas primeiras semanas de uma campanha, o resultado incremental de vendas tende a ser crescente mesmo quando a intensidade de mídia é mantida (wearin) e passa a 
reduzir-se nas semanas seguintes (wearout). No Gráfico 6, ilustra-se bem esse efeito.

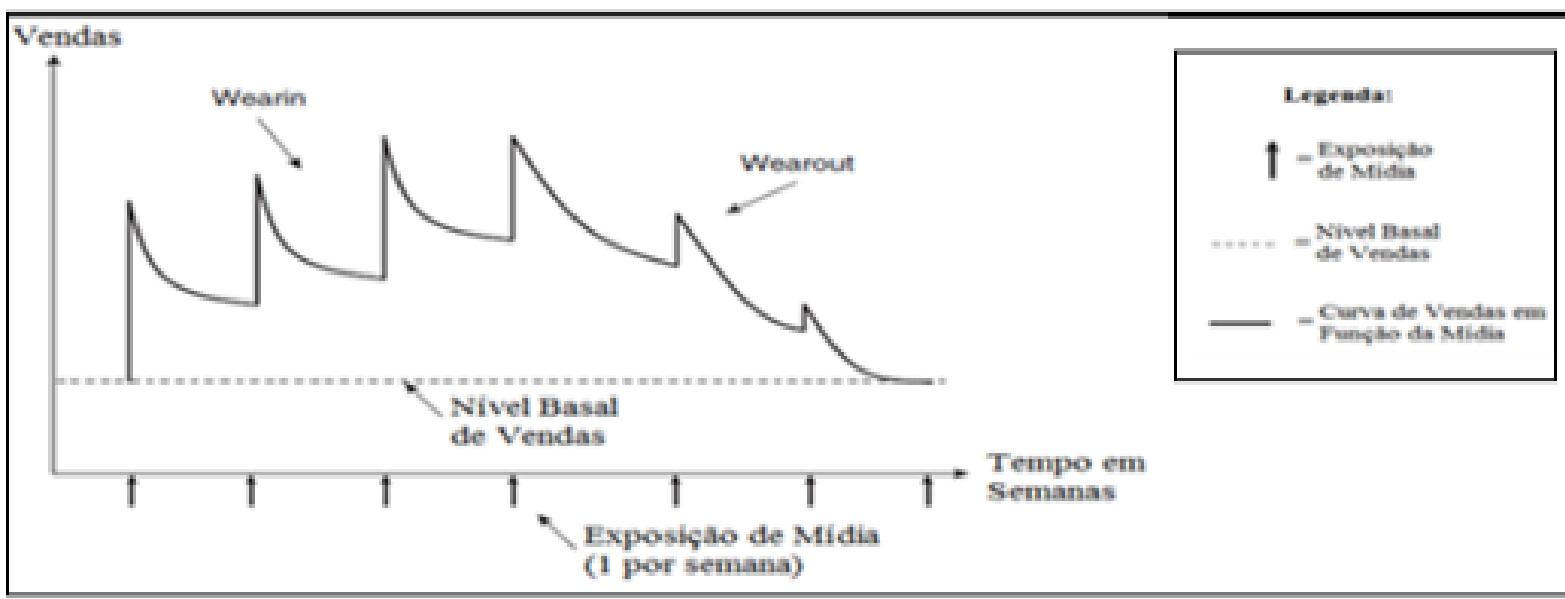

\section{Gráfico 5: Efeitos de wearin e wearout em resposta à exposição de mídia}

Fonte: Adaptado de Tellis (2006)

\section{METODOLOGIA DA PESQUISA}

Esta pesquisa aplicada é de natureza exploratória, pois permite que se tenha maior familiaridade com o problema estudado e é bastante aplicada quando há variáveis importantes que podem não ser conhecidas ou não estar totalmente definidas. O método adotado foi o de um estudo de caso único com base em análise de dados quantitativos secundários de uma empresa do segmento de telecomunicações. Ainda que não se trate de uma pesquisa qualitativa, a utilização de um estudo de caso justifica-se pela abordagem em um caso e circunstâncias bastante específicas (Eisenhardt, 1989; Gil, 2010).

Para fins de simplificação da análise, optou-se por avaliar exclusivamente o mercado de banda larga residencial desta empresa, nas cidades de São Paulo e Rio de Janeiro, no período compreendido entre julho de 2012 e abril de 2013. Esse período justifica-se por haver investimento de mídia apenas nessas praças no período. 
As seções seguintes tratarão em detalhe sobre como se deu a coleta e a análise de dados do caso, fechando-se com um quadro que sintetiza os procedimentos metodológicos.

\subsection{ANÁLISE DOS DADOS}

Conforme abordado no capítulo anterior e representado no Gráfico 7, a forma que mais se assemelha ao efeito de vendas em relação à intensidade de mídia é o S. Essa curva, no entanto, tem uma grande extensão linear, permitindo a aproximação dessa forma a uma reta. Partindo dessa premissa, optou-se pela simplificação do modelo, fazendo a análise de dados por meio de uma regressão linear. Essa opção justifica-se também pela necessidade de tornar a modelagem uma atividade aplicável no ambiente corporativo por profissionais com conhecimentos básicos de estatística via uma ferramenta amplamente utilizada pelos profissionais de marketing: o Microsoft Excel. A seguir, há a representação gráfica e a equação de uma regressão:

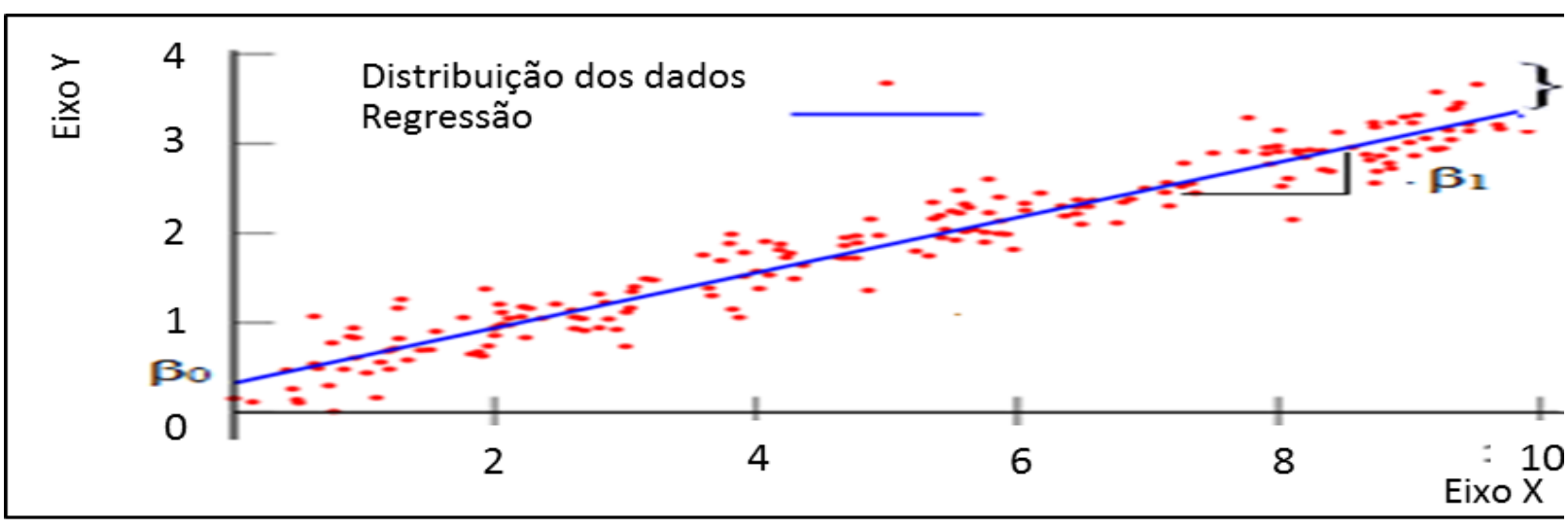

Gráfico 6: Representação gráfica de regressão linear simples

Fonte: Os autores

$$
\mathbf{E}(Y)=\beta_{0}+\beta_{1} X+e
$$

em que:

Y = variável dependente

$\beta 1=$ coeficiente angular

$\beta 0=$ intercepto populacional

$X=$ variáveis independentes

e $=$ erro aleatório. 
Dado que há uma série de variáveis - tanto dentro do universo de mídia (diferentes veículos de comunicação e formatos), como de oferta (variação de preço ao longo do tempo) e mercado (sazonalidade, contexto macroeconômico, etc.) - que impactam diretamente no resultado de vendas, a regressão linear múltipla, e não simples, foi fundamental. Neste tipo de modelagem, há duas ou mais variáveis que impactam no valor de $\mathrm{Y}$, conforme função a seguir:

$$
\mathbf{E}(Y)=\beta_{0}+\beta_{1} X_{1}+\ldots+\beta_{p} X_{p}+e
$$

em que:

Y = variável dependente

$\beta 0=$ intercepto populacional

$\beta 1, \ldots, \beta p=$ coeficientes angulares

$\mathrm{X} 1, \ldots, \mathrm{XP}=$ variáveis independentes

e $=$ erro aleatório

Para este estudo, foram feitas duas modelagens, uma para cada canal de vendas receptivo da empresa: televendas receptivo e website. Optou-se por realizar o estudo apenas em canais receptivos, partindo-se da premissa de que, na expressiva maioria das vezes, os clientes buscam a empresa, geralmente, motivados pela ação de comunicação. Ou seja, as vendas geradas nesses canais são mais "puras", não sofrendo assim interferência de estratégias de vendas diretas.

O tratamento estatístico dos dados foi feito na ferramenta Microsoft Excel.

\subsection{COLETA DE DADOS}

Todos os dados utilizados neste modelo são secundários. Foram obtidos por meio de relatórios internos da empresa, relatórios da agência de comunicação e bases de institutos amplamente conhecidos no Brasil: Ibope, Ipea e Google Analytics. 
As variáveis dependentes definidas para a modelagem (Y1 e Y2) não são o resultado de venda da empresa em si, estão no estágio imediatamente anterior. Correspondem ao momento em que o potencial cliente entrou em contato com os canais de venda receptivos, a seguir detalhados, com a intenção de comprar ou conhecer melhor o produto. Para que a venda seja efetivada, além do interesse do cliente pelo produto, é preciso que duas condições sejam atendidas:

1) haver viabilidade técnica para habilitação da banda larga na residência, uma vez que a cobertura nos municípios de São Paulo e Rio de Janeiro é parcial. Além disso, há casos em que há cobertura em uma determinada região, porém é identificada posteriormente uma obstrução predial que inviabiliza a venda final;

2) o cliente não ter débito no Serasa. Esta é uma política da empresa analisada para redução do risco de inadimplência futura.

Y1 = chamadas recebidas - corresponde ao total de chamadas atendidas pelo televendas receptivo, que corresponde à etapa 4 da Figura 1. As chamadas são direcionadas para o Televendas (atendimento de venda humano) após realização de dois filtros: validação se já é cliente e do local de residência da pessoa.

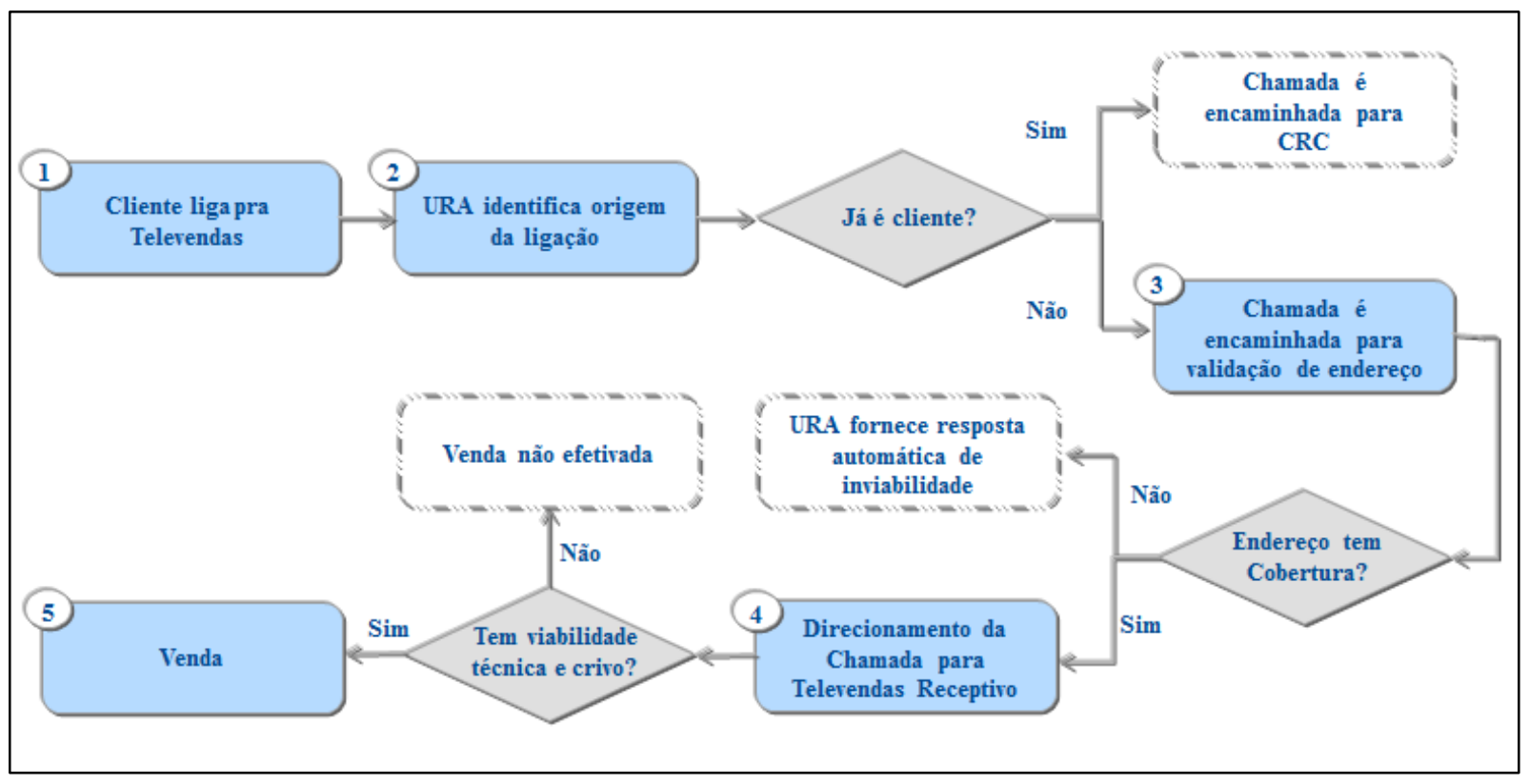

Figura 1: Fluxo de venda simplificado do televendas receptivo

Fonte: Os autores 
Y2 = visitantes únicos - corresponde ao total de visitantes únicos no portal de vendas do website da empresa de banda larga residencial. Deste número subtraiu-se o total de visitantes provenientes de ações de mídia na internet, uma vez que a origem desses visitantes já é conhecida (Google Analytics, 2014).

As bases de dados de chamadas recebidas no televendas e de visitantes únicos no website não possuíam no período da coleta de dados abertura por praça, não sendo possível atribuir o peso de cada praça no resultado do canal de venda. Por esse motivo, optou-se por analisar as duas praças, Rio de Janeiro e São Paulo, em conjunto, mesmo entendendo-se que o comportamento do mercado consumidor em mercados diferentes pode ser diferente. Para minimizar os possíveis impactos dessa análise conjunta das praças, tomou-se o cuidado de não utilizar métricas de intensidade de mídia que não fossem comparáveis. Dessa forma, entende-se que não houve erro conceitual na atribuição de resultado para cada meio ou formato analisado no modelo. Por outro lado, o resultado expresso nos meios jornal e rádio corresponderá ao resultado médio do desempenho dos mesmos em cada praça e não em cada uma isoladamente.

Antes de apresentar todas as variáveis independentes testadas neste modelo, é importante fazer uma breve introdução sobre a escolha delas. Além das mídias tradicionais de massa - TV, rádio, jornal, etc. -, incluíram-se outros instrumentos de comunicação de marketing, dentre eles relações públicas (imprensa especializada, blogueiros e formadores de opinião), mala direta, e-mail marketing e patrocínios e eventos, que compõem a estratégia de comunicação e contribuem para o resultado final dos canais de venda, ainda que alguns deles não envolvam diretamente a compra de mídia e possam ser resultado de uma ação externa à empresa, como é o caso da atuação da imprensa.

Adicionalmente, conforme exposto na seção de fundamentação teórica, o efeito de mídia varia não apenas quando há mudança de meio de comunicação, mas também no formato desta. Por exemplo, as inserções avulsas de TV podem ter a mesma intensidade de Target Rating Point (TRP), porém duração diferente, variando de 15 a 120 segundos; ainda que a tiragem seja a mesma, a alocação do conteúdo publicitário no jornal pode ser 
na capa ou dentro de um caderno secundário; e assim por diante. Entendendo-se essa diferença como fundamental, tanto no resultado de venda como no valor de compra do espaço publicitário, os meios que tiverem formatos de compra essencialmente diferentes no caso estudado, foram tratados separadamente no modelo. Não se diferenciou neste estudo, por exemplo, a compra de TV em formatos de 15 e 30 segundos, mas a compra desses formatos ao de 90 segundos. Com isso, tem-se um modelo que mede não apenas o meio mais eficaz, mas também o formato.

Por fim, mesmo sendo um dos objetivos centrais do trabalho a determinação do resultado de vendas gerado pelo esforço de comunicação, é preciso levar em conta que outras variáveis de mercado impactam significativamente, em especial a oferta. Na pesquisa realizada por Sethuraman e Tellis (1991), por exemplo, determinou-se que a elasticidade média de preço é em média 14,6 vezes maior do que a de comunicação para geração de vendas, conforme análise feita em 130 marcas de produtos avaliados no período.

No Quadro 1, sintetizam-se as variáveis Xp avaliadas em cada canal de venda receptivo, descrevendo-se a quantidade de formatos ou variáveis avaliadas, unidade de medida e fonte secundária de dado. Nas colunas "Televendas receptivo (Y1)" e "Website (Y2)", "Sim" corresponde à utilização da variável no modelo do respectivo canal de venda. 


\begin{tabular}{|c|c|c|c|c|c|c|}
\hline Tipo & Nome & $\begin{array}{l}\text { Quantidade } \\
\text { de variáveis }\end{array}$ & Unidade de Medida & $\begin{array}{c}\text { Televendas } \\
\text { Receptivo } \\
\text { (Y1)* }\end{array}$ & $\begin{array}{l}\text { Website } \\
\text { (Y2)* }\end{array}$ & $\begin{array}{c}\text { Fonte do } \\
\text { Dado }\end{array}$ \\
\hline \multirow{4}{*}{$\begin{array}{l}\text { Meios de } \\
\text { Massa de } \\
\text { Comunicação }\end{array}$} & TV & 3 & Volume de TRPs & $\operatorname{Sim}$ & $\operatorname{Sim}$ & \multirow{3}{*}{$\begin{array}{l}\text { IBOPE } \\
\text { Monitor }\end{array}$} \\
\hline & Rádio & 2 & Quantidade de inserções & $\operatorname{Sim}$ & $\operatorname{Sim}$ & \\
\hline & Jornal & 2 & Tiragem do jornal & Sim & $\operatorname{Sim}$ & \\
\hline & Internet & 8 & $\begin{array}{l}\text { Tráfego de Origem do } \\
\text { Website }\end{array}$ & Não & Sim & $\begin{array}{l}\text { Google } \\
\text { Analytics }\end{array}$ \\
\hline \multirow{3}{*}{$\begin{array}{l}\text { Formatos } \\
\text { Alternativos de } \\
\text { Comunicação }\end{array}$} & $\begin{array}{l}\text { Relações } \\
\text { Públicas }\end{array}$ & 1 & Variável Dummy & Sim & Sim & \multirow{3}{*}{$\begin{array}{l}\text { Relatórios } \\
\text { Internos da } \\
\text { Empresa }\end{array}$} \\
\hline & Eventos & 1 & Quantidade de inserções & Sim & Sim & \\
\hline & Mala Direta & 1 & Tiragem da mala & $\operatorname{Sim}$ & $\operatorname{Sim}$ & \\
\hline \multirow{4}{*}{$\begin{array}{l}\text { Outras } \\
\text { Variáveis }\end{array}$} & Ofertas & 3 & Variável Dummy & $\operatorname{Sim}$ & $\operatorname{Sim}$ & \multirow{3}{*}{$\begin{array}{l}\text { Relatórios } \\
\text { Internos da } \\
\text { Empresa }\end{array}$} \\
\hline & \begin{tabular}{|l} 
Cobertura de \\
Rede
\end{tabular} & 1 & $\begin{array}{l}\text { Quantidade de residências } \\
\text { cobertas }\end{array}$ & Não & Sim & \\
\hline & Filtro da URA & 1 & $\begin{array}{l}\text { Quantidade de CEPs com } \\
\text { residências cobertas }\end{array}$ & Sim & Não & \\
\hline & $\begin{array}{l}\text { Vendas Nominais } \\
\text { do Varejo }\end{array}$ & 1 & $\begin{array}{l}\text { Valor em } \mathrm{R} \$ \text { de Venda } \\
\text { Nominal do Varejo }\end{array}$ & Sim & Sim & IPEA Data \\
\hline
\end{tabular}

Quadro 1: Descrição das variáveis independentes (Xp) do modelo

Fonte: Os autores

\section{DISCUSSÃO E ANÁLISE DOS RESULTADOS}

Para iniciar esta seção, faz-se necessário esclarecer que, para a elaboração deste estudo de caso, foram usadas informações confidenciais da empresa escolhida, que não autorizou a divulgação completa das bases de dados fornecidas. Por esse motivo, para evidenciar a metodologia adotada, as variáveis dependentes foram denominadas genericamente de $\mathrm{X} 1, \mathrm{X} 2$ e assim por diante, e os valores dos gráficos tiveram um coeficiente aplicado, não correspondendo aos reais.

Antes de apresentar-se o resultado da modelagem em si, cabe retomar os efeitos do composto de marketing sobre as vendas, abordados no capítulo de fundamentação teórica, demonstrando, com base nesses conceitos, as principais contribuições e limitações do modelo adotado. 


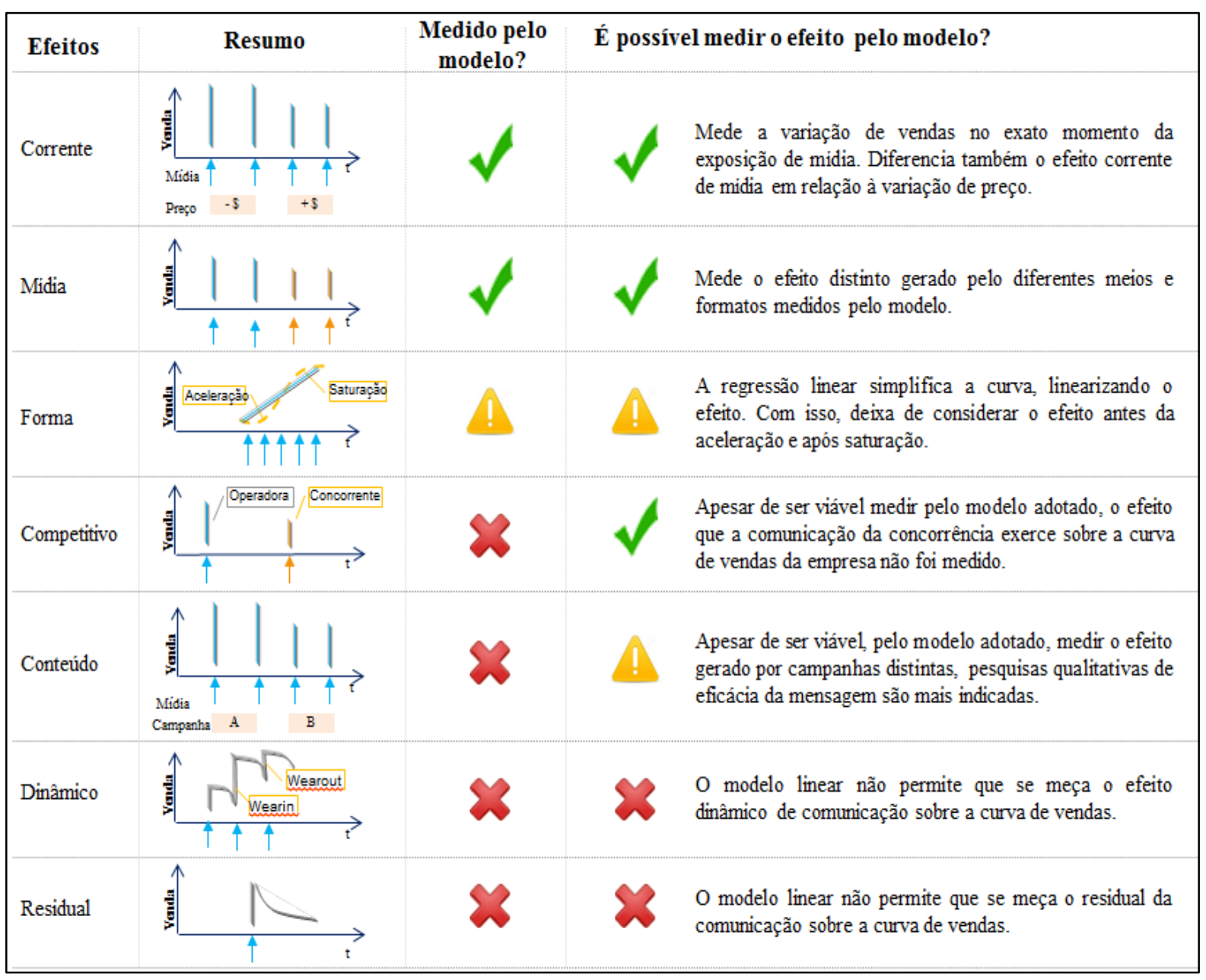

Figura 2: Efeitos medidos pelo modelo

Fonte: Os autores

Na Figura 2, evidencia-se o foco da pesquisa nos efeitos corrente e mídia. Atendendo a esses dois quesitos, portanto, o objetivo da modelagem terá sido atingido. A ressalva principal que se faz nesta seção é em relação ao efeito competitivo. Variáveis independentes referentes a esse efeito como valor investido pelos concorrentes ou até mesmo variáveis que refletissem o contexto macroeconômico - não foram incluídas nesta modelagem em função da ferramenta utilizadas para análise, o Microsoft Excel, que limita a quantidade total de variáveis testadas simultaneamente em um único modelo.

No Gráfico 8, demonstra-se o resultado obtido após realização da regressão linear múltipla das chamadas recebidas no televendas receptivo. Chegou-se a um coeficiente de determinação de 96,2\% e R2 ajustado de $90,4 \%$, valores estatisticamente bastante significativos, pois estão próximos 
a $100 \%$, valor máximo. Com relação às 15 variáveis independentes testadas, descritas no capítulo de metodologia, 11 tiveram alto nível de correlação e quatro foram reprovadas pelo modelo e por isso retiradas da análise.

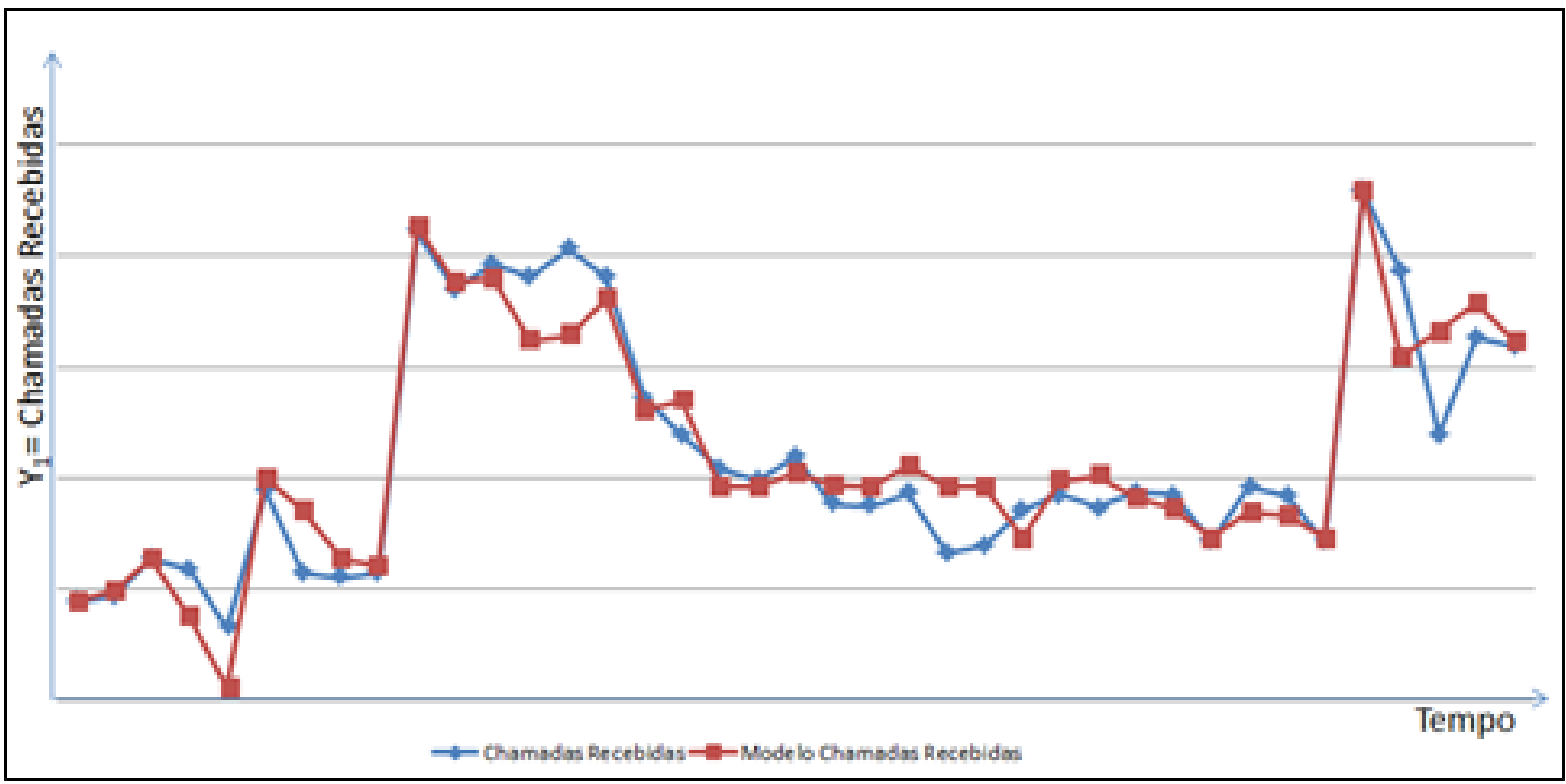

\section{Gráfico 8: Comparação entre curva de chamadas recebidas real e modelagem}

Fonte: Os autores

Já no Gráfico 9, demonstra-se o resultado obtido na regressão linear múltipla dos visitantes únicos no website da empresa. Conforme demonstrado no gráfico, chegou-se a resultados bastante semelhantes: coeficiente de determinação de 96,4\% e R2 ajustado de 90,1\%, valores estatisticamente bastante significativos, pois estão próximos a $100 \%$, valor máximo. As oito variáveis independentes de internet não foram testadas no modelo, pois o valor de resultado já era conhecido. Elas passaram a compor o modelo na etapa posterior de análise, que será descrita no parágrafo seguinte. Com relação às 15 variáveis independentes testadas, também descritas no capítulo de metodologia, 12 tiveram alto nível de correlação e três foram reprovadas pelo modelo e por isso retiradas da análise. 


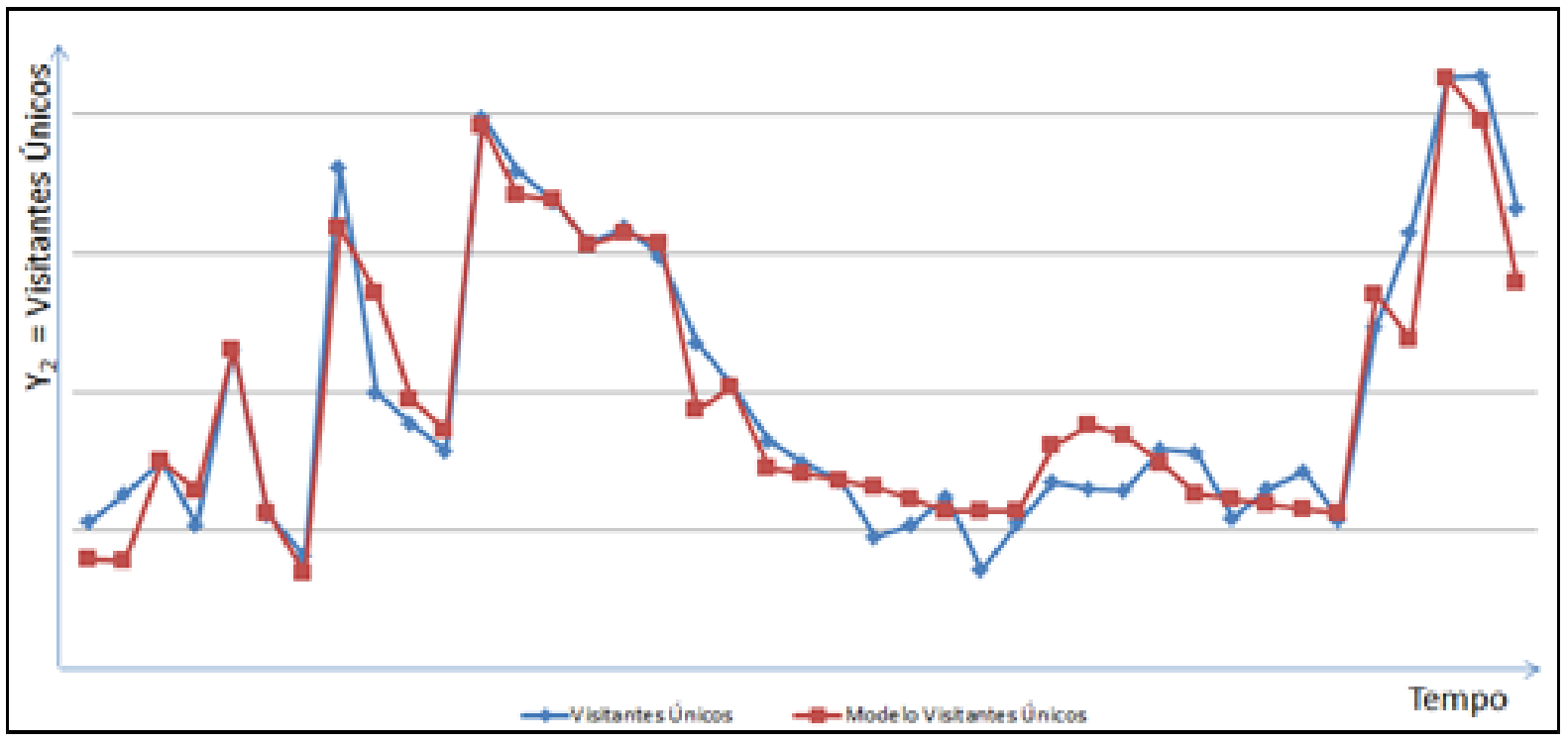

\section{Gráfico 9: Comparação entre curva visitantes únicos real e modelagem}

Fonte: Os autores

As variáveis independentes podem não estar correlacionadas à variável dependente por três motivos: 1) a variável de fato não gera alteração nos níveis de chamada ou visitantes únicos independentemente da intensidade que apresente; 2) o resultado observado pela variável não é necessariamente linear, podendo, portanto, haver correlação de outra natureza: exponencial, polinomial, etc.; 3) a variável analisada não é linearizável dentro de determinado domínio, ou seja, não atingiu intensidade mínima para adquirir comportamento linear, ou já apresenta comportamento de saturação. As mesmas três variáveis independentes não tiveram correlação linear nos dois modelos testados, com exceção de uma que foi testada exclusivamente no modelo de chamadas recebidas. Por meio deste estudo de caso, não se pode afirmar o motivo exato de essas variáveis não apresentarem correlação, mas há indícios de que esse comportamento seja reflexo da baixa intensidade de investimento a elas relacionada.

No Gráfico 10, demonstra-se o resultado total de chamadas recebidas, o montante investido e o custo por resultado incremental atribuídos a cada meio ou formato de comunicação, trazendo uma importante visão de eficiência de mídia tendo como foco a maximização do resultado no televendas receptivo da empresa analisada. Observa-se pelo comportamento das curvas, que não há uma relação direta entre o volume investido e o 
resultado gerado, demonstrando que há alternativas mais eficientes no processo decisório da empresa. A variável independente $\mathrm{X} 4$, por exemplo, foi a que teve o segundo maior investimento dentre os meios e formatos avaliados, porém apresentou a pior relação investimento por resultado incremental.

\section{Total de Chamadas Recebidas}

Valor total gerado por cada variável independente, de acordo com resultado do modelo

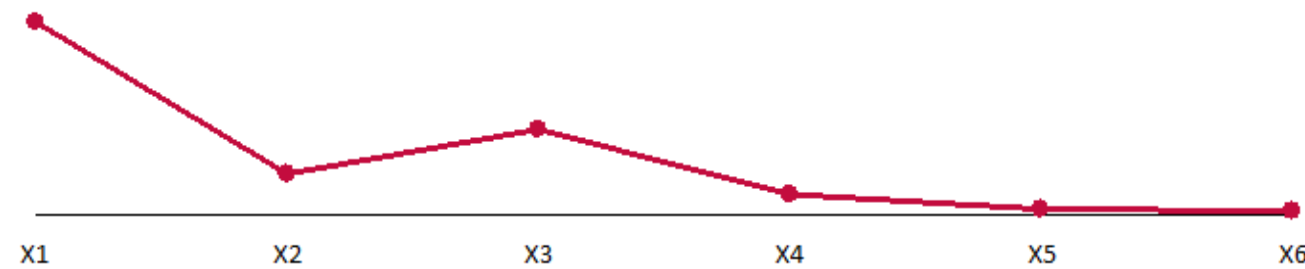

Total de Investimento

Valor total em R\$় investido em cada variável independente estudada no modelo

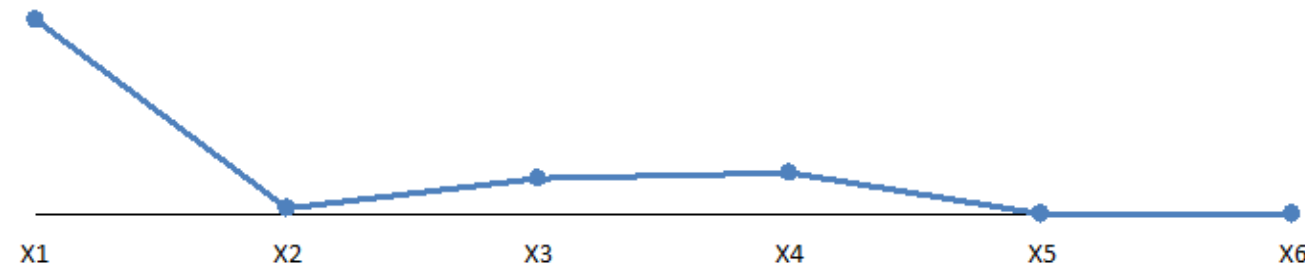

Investimento por Resultado Incremental

Valor total investido em $\mathrm{R} \$$ dividido pelo total de chamadas recebidas de cada variável independente

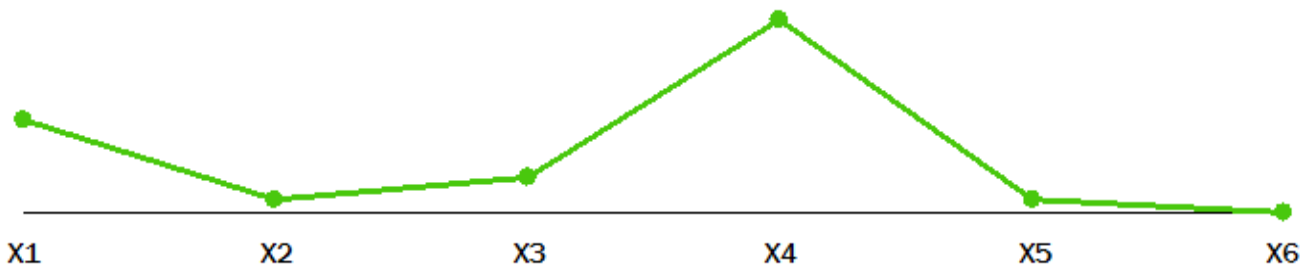

Sendo $\mathrm{X} 1, \mathrm{X} 2 \ldots \mathrm{X} 8$, as variáveis dependentes do composto de comunicação

Gráfico 10: Eficiência do investimento em comunicação no televendas receptivo

Fonte: Os autores

No Gráfico 11, demonstra-se o resultado total de visitantes únicos, o montante investido e o custo por resultado incremental atribuídos a cada meio ou formato de comunicação, trazendo uma importante visão de eficiência de mídia tendo como foco a maximização do resultado no website da empresa analisada.

Assim como no televendas receptivo, observa-se, pelo comportamento das curvas, que não há uma relação direta entre o volume investido e o resultado gerado, demonstrando que há alternativas mais 
eficientes no processo decisório da empresa. A variável independente $\mathrm{X} 2$, por exemplo, foi a que teve o maior investimento dentre os meios e formatos avaliados e apresentou a pior relação investimento por resultado incremental.

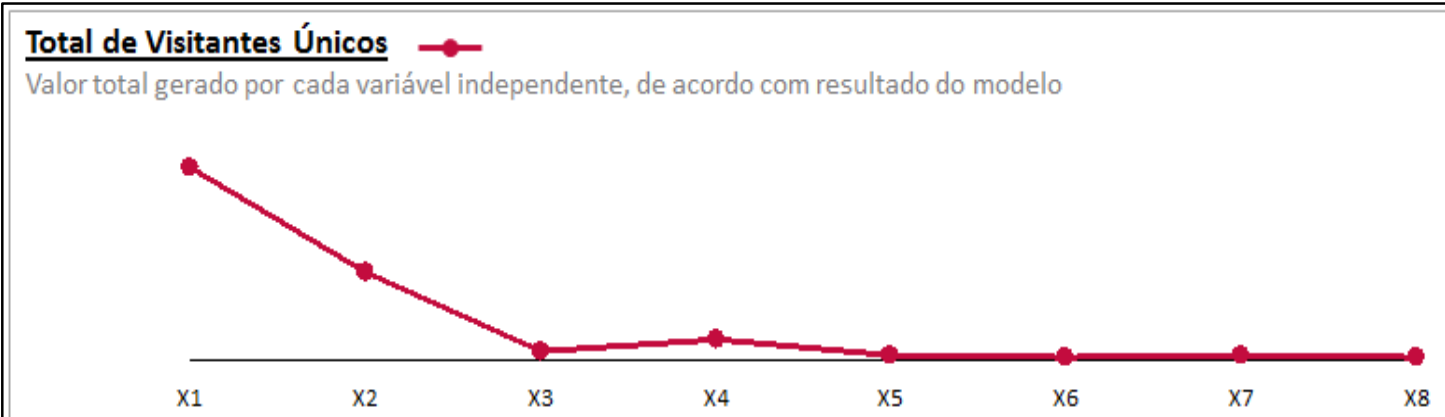

Total de Investimento

Valor total em R\$̣ investido em cada variável independente estudada no modelo

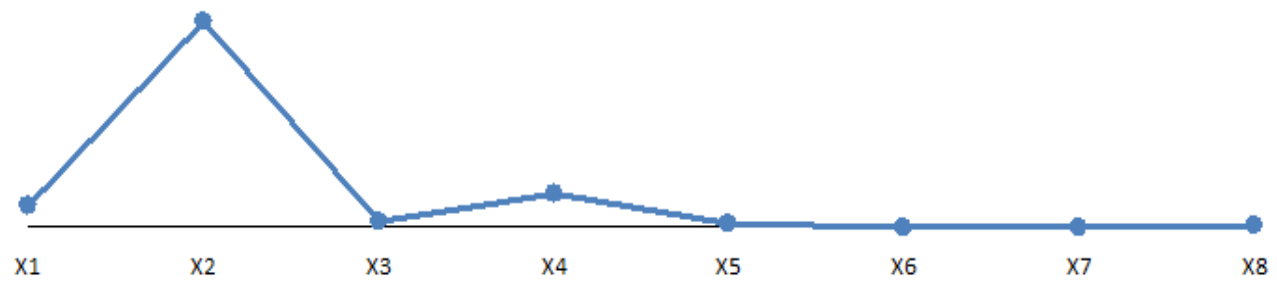

Investimento por Resultado Incremental

Valor total investido em R\$ dividido pelo total de visitante únicos de cada variável independente

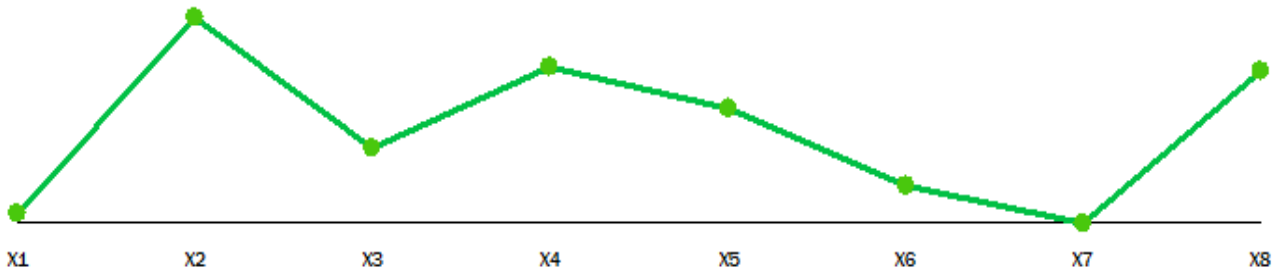

Sendo $\mathrm{X} 1, \mathrm{X} 2$... X8, as variáveis dependentes do composto de comunicação

\section{Gráfico 11: Eficiência do investimento em comunicação no website da empresa}

Fonte: Os autores

Como primeira conclusão importante deste capítulo, tem-se que os valores obtidos de coeficiente de correlação e R2 ajustado, ambos acima de $90 \%$, demonstram que a representação linear é adequada para a modelagem do composto de marketing da empresa estudada, dentro do nível de investimento apresentado, e que a parte mais significativa das variáveis independentes que influenciam o comportamento dos canais receptivos da empresa já é conhecida.

É possível verificar também que há oportunidade de melhoria do mix de mídia da empresa avaliada para otimização do investimento e aumento da 
eficiência de mídia. Em geral, os meios e os formatos que mais receberam aporte de investimento não tiveram melhor performance, enquanto outros com investimento menos representativo demonstraram potencial para alavancar o resultado da empresa, ao apresentar melhor custo-benefício, representado pelo custo por resultado incremental dos Gráficos 10 e 11 .

\section{CONSIDERAÇÕES FINAIS}

No trabalho, atingiu-se o objetivo geral de identificar os meios de comunicação mais eficazes nos canais de venda receptivos em uma empresa de telecomunicações, por meio de um método capaz de destacar o resultado gerado por cada elemento do composto de marketing, otimizando o investimento de comunicação. Utilizou-se, para isso, uma abordagem contemporânea do conceito de eficácia de mídia, com métricas diferentes de cobertura e frequência amplamente utilizadas entre profissionais de comunicação, tanto em empresas como em agências de comunicação.

Para o meio empresarial, o trabalho cumpre o papel de auxiliar os gestores na tomada de decisão sobre o investimento de comunicação, montante bastante significativo na linha de orçamento, em especial nas do setor de telecomunicações. Para a academia, tem-se um tema pouco explorado e um estudo de caso inédito no país, tomando como base as referências bibliográficas estudadas.

O estudo é, portanto, um ponto de partida tanto para o meio científico quanto empresarial, com potencial para tornar-se uma das ferramentas mais importantes para decisões relativas e eficácia de mídia nas organizações. Para isso, propõe-se a complementação desta metodologia com a construção de modelos preditivos de venda e de um novo modelo matemático que sugira 0 mix de mídia que maximiza o resultado de vendas, ambos usando como base os insumos fornecidos pela modelagem estatística.

Como sugestão de estudos futuros, recomenda-se ainda testar o enriquecimento da modelagem com informações externas à empresa, conforme o que segue:

1) competidores: dados como variações, no mercado, do preço ofertado e do investimento em comunicação; 
2) variação dos principais indicadores macroeconômicos: inflação, índice de emprego, taxa de crescimento do setor. Para que isso seja possível, será necessária a mudança de ferramenta de análise dos dados, dada a limitação de variáveis independentes que o Microsoft Excel permite modelar simultaneamente.

\section{REFERÊNCIAS}

Anderson, C. (2008). Free! Why $\$ 0,00$ is the future of business. Recuperado em 18 de fevereiro, 2015, de http://www. wired.com/techbiz/it/magazine/1603/ff_free?currentPage=all.

Briggs, R., Krishnan, R., \& Borin, N. (2005). Integrated multichannel communication strategies: evaluating the return on marketing objectives - the case of the 2004 Ford F-150 launch. Journal of Interactive Marketing, 19(3), 81-90.

Chimenti, P.,\& Nogueira, A. (2007). O desafio estratégico das novas tecnologias na indústria da propaganda: um estudo de caso. Anais de Encontro de Administração da Informação - Enadi, Florianópolis, SC, Brasil.

Coulter, K., \& Sarkis, J. (2005). Development of a media selection model using the analytic network process. International Journal of Advertising: The Quarterly Review of Marketing Communications, 24(2), 193-216.

Court, D. C., Gordon, J. W., \& Perrey, J. (June, 2005). Boosting returns on marketing investment. The McKinsey Quarterly, 2, 36-47.

Crescitelli, E., \& Shimp, T. A. (2012). Comunicação de marketing: integrando propaganda, promoção e outras formas de divulgação. São Paulo: Cengage Learning, 2012.

Dimmick, J., Kline, S., \& Stafford, E. (2004). The gratification niches of personal e-mail and the telephone. Communication Research, 27(2), 227248.

Donaton, S. (2004). Why the entertainment \& advertising industries must converge to survive. New York: Mc Graw-Hill.

Eisenhardt, K. M. (1989). Building theories from case study research. Academy of Management Review, 14(4), 532-550.

Ephron, E. (1995). More weeks, less weight: the shelf-space model of advertising. Journal of Advertising Research, 35(3), 18-23.

Gil, A. C. (2010). Como elaborar projetos de pesquisa (5a ed.). São Paulo: Atlas. 
Google Analytics. (2014). Recuperado em 20 de abril, 2014, de https://www.google.com/analytics.

Instituto Brasileiro de Opinião Pública e Estatística - Ibope. (2015). Anunciantes - 30 maiores - 2013 - ano. Recuperado em 22 de fevereiro, 2015, de http://www.ibope.com.br/ptbr/conhecimento/TabelasMidia/investimentopublicitario/ Paginas/ANUNCIANTES-\%E2\%80\%93-30-MAIORES---1\%C2\%BASEMESTRE-2013.aspx.

Ibope Monitor (2015). Informações coletadas do portal IBope Monitor.

McCarthy, E. J. (1996). Basic marketing: a managerial approach (12th ed.). Homewood: R. D. Irwin.

Rodrigues, M. A. S., Chimenti, P., \& Nogueira, A. R. R. (2012). O impacto das novas mídias para os anunciantes brasileiros. Revista de Administração, 47(2), 249-263.

Rodrigues, M. A. S., Chimenti, P. C. P. S., Nogueira, A. R. R., \& Vaz, L. F. H. (2013). Métricas, mídias e anunciantes: discutindo a relação. Anais do Encontro Anual da Associação Nacional de Pós-Graduação e Pesquisa em Administração, 37, Rio de Janeiro, RJ, Brasil.Sethuraman, R.; Tellis, G. J. (1991). An analysis of the tradeoff between advertising and price discounting. Journal of Marketing Research, 31(2), 160-174.

Shen, F. (2002). Banner advertisement pricing, measurement, and pretesting practices: perspectives from interactive agencies. Journal of Advertising, v.31, issue 3, p.59-67.

Steinberg, B. (November, 2009). The future of TV: we'll be ordering up our own video, ads and products on a web convergence device. But who will reap the revenue? Advertising Age, New York. Recuperado em: 20 de abril, 2014, de http://adage.com/article/media/future-tv/140751/.

Tellis, G. J. (2006). Modeling marketing mix. In R. Grover, \& M. Vriens (Eds.). The handbook of marketing research (Chap. 24, pp. 506-522). Thousand Oaks: Sage. 